\title{
The alteration of Lipids and Steroid Hormones in Breast Tumors
}

N. Kotrikadze ${ }^{1}$, I. Nakashidze ${ }^{2,4}$, L. Ramishvili1, M. Alibegashvili', N. Petrovic ${ }^{3}$, T. Peshkova $^{4}$, B. Sepiashvili', M. Gordeziani ${ }^{1}$, S. Gufta ${ }^{4}$, M. Vanidze ${ }^{5}$, A. Kalandia ${ }^{5}$, S. Ahmad'.

${ }^{1}$ Ivane Javakhishvili Tbilisi State University, Department of Biology, Tbilisi, Georgia. 2Batumi Shota Rustaveli State University, Department of Biology, Batumi, Georgia. ${ }^{3}$ Vinca Institute of Nuclear Sciences University of Belgrade, Department for Radiobiology and Molecular Genetics, Belgrade, Serbia.

${ }^{4}$ Batumi Shota Rustaveli State University, Department of Clinical Medicine, Batumi, Georgia.

${ }^{5}$ Batumi Shota Rustaveli State University, Department of Biochemistry, Batumi, Georgia. ${ }^{6}$ Florida Hospital Cancer Institute, Department of Gynecologic Oncology, Orlando, FL, USA

Objectives: Breast Cancer (BC) is the mostly spread malignant disease among women worldwide. Lipids play important roles in several biochemical pathways on molecular and cellular level, such as synthesis of steroid hormones, which contributes to the development of $\mathrm{BC}$. Therefore, we investigated levels following plasma lipids: cholesterol (TC), high-density lipoprotein (HDL), low-density lipoprotein (LDL), very low-density lipoprotein (VLDL) and triglycerides (TG), and sex-steroid hormones: progesterone $(P)$, estradiol (E2) and testosterone $(T)$ in pre-menopausal (2045 years) women with benign or malignant breast tumors.

Methods: We studied the lipid profile among the premenopausal (20-45 years) women with breast tumors. Venous blood samples were tested for investigation investigation. $\mathrm{P}<$ 0.05 was regarded as statistically significant.

Results: According to our investigation, higher $\mathrm{CHOL}$ level were associated with benign $(P=0.0002)$, and malignant $(P=0.0001)$ tumors compared with control group. The level of $\mathrm{HDL}$ decreases in benign $(P=0.0002)$ and malignant $(P<0.001)$ tumor groups compared with the control group. LDL level was elevated in both groups, as well, in benign and malignant tumors respectively $(P=0.002, P<0.001)$. VLDL level was also decreased in both tumor subtypes respectively $(P=0.0003 ; P=0.0007)$ compare to control group. Similarly, TG level was increased in benign ( $P=0.0025)$, and in malignant breast tumors $(P=0.002)$ compared with controls. E2 and $\mathrm{T}$ levels were elevated in tumors in tumor's group $(P<0.05)$.

Conclusions: Our investigation has shown the association between high levels of CHOL, LDL,TG, E2 and T with breast tumors. Lipid profile and steroid hormones may be used as relatively reliable prognostic marker for early breast cancer prevention and diagnostics

Table 1. Alteration of Lipids in Breast Tumors (Benign, Malignant).

\begin{tabular}{clll} 
Lipids & $\begin{array}{c}\text { Control } \\
\text { group }\end{array}$ & \multicolumn{1}{c}{ Benign Tumor } & $\begin{array}{c}\text { Malignant } \\
\text { Tumor }\end{array}$ \\
Cholesterol & $194 \pm 4.98$ & $\begin{array}{l}232 \pm 3.65 \\
\mathrm{P}=0.0002\end{array}$ & $\begin{array}{l}267 \pm 8.35 \\
\mathrm{P}=0.0001\end{array}$ \\
& & & $38.40 \pm 1.28$ \\
High-Density & $51.30 \pm 0.8$ & $40.80 \pm 2.35$ & $\mathrm{P}<0.001$ \\
Lipoproteins & & $\mathrm{P}=0.0002$ & $186.6 \pm 4.62$ \\
Low-Density & $136.1 \pm 5.23$ & $165.8 \pm 2.28$ & $\mathrm{P}<0001$ \\
Lipoproteins & & $\mathrm{P}=0.002$ & $22.2 \pm 1.24$ \\
Very-Low-density & $37.80 \pm 1.84$ & $23.40 \pm 1.45$ & $\mathrm{P}=0.0007$ \\
Lipoproteins & 3 & $\mathrm{P}=0.0003$ & $164.4 \pm 3.14$ \\
Triglycerides & $142.7 \pm 2.48$ & $156.6 \pm 1.53$ & $\mathrm{P}=0.002$
\end{tabular}

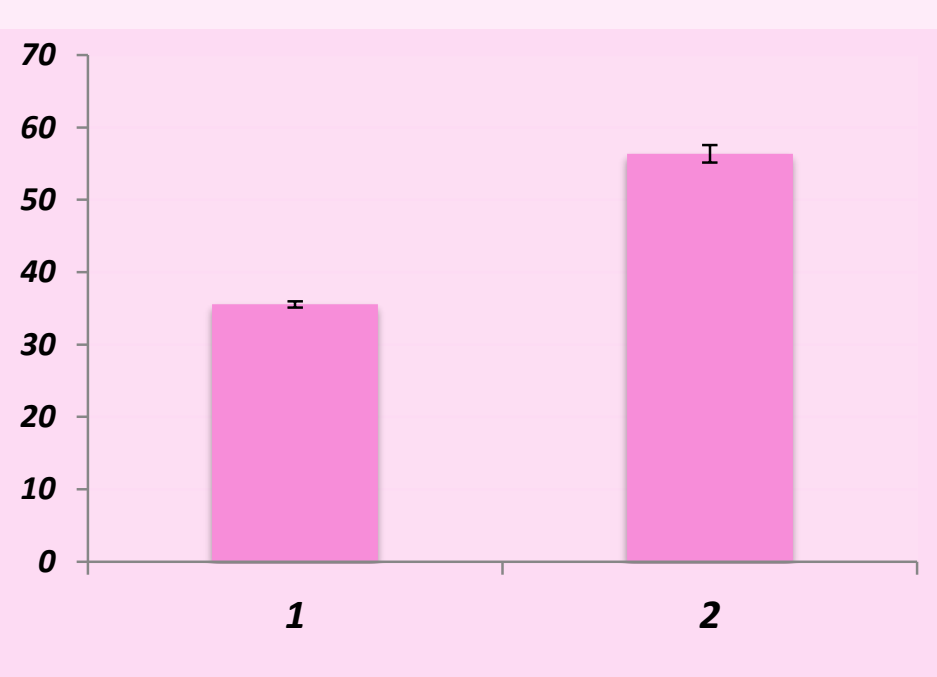

Fig. 1. a. E2.

1. Control group; 2. Benign Tumor.

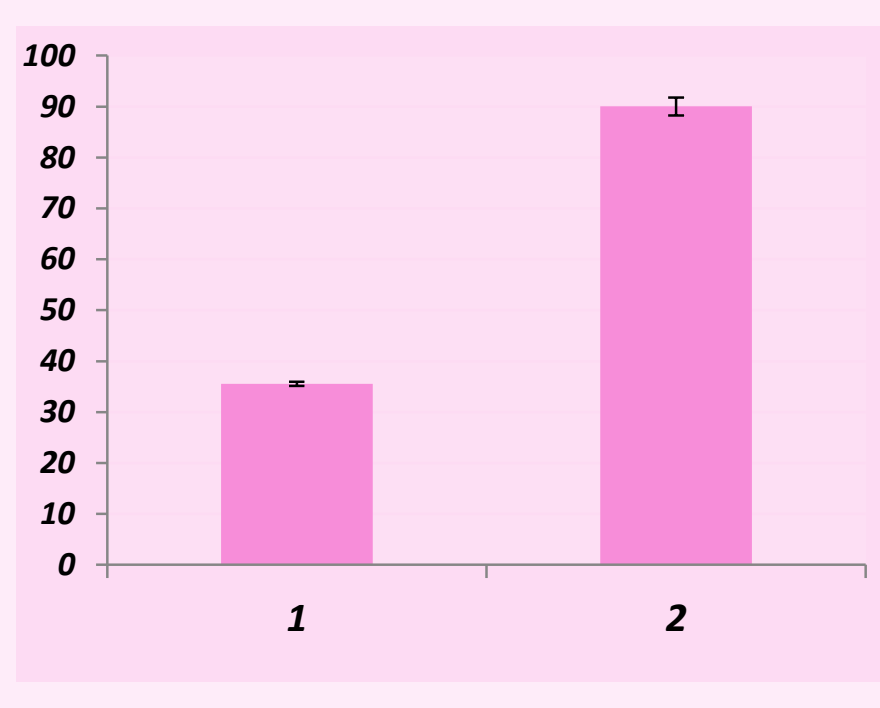

b. E2. 1. Control group; 2. Cancer.

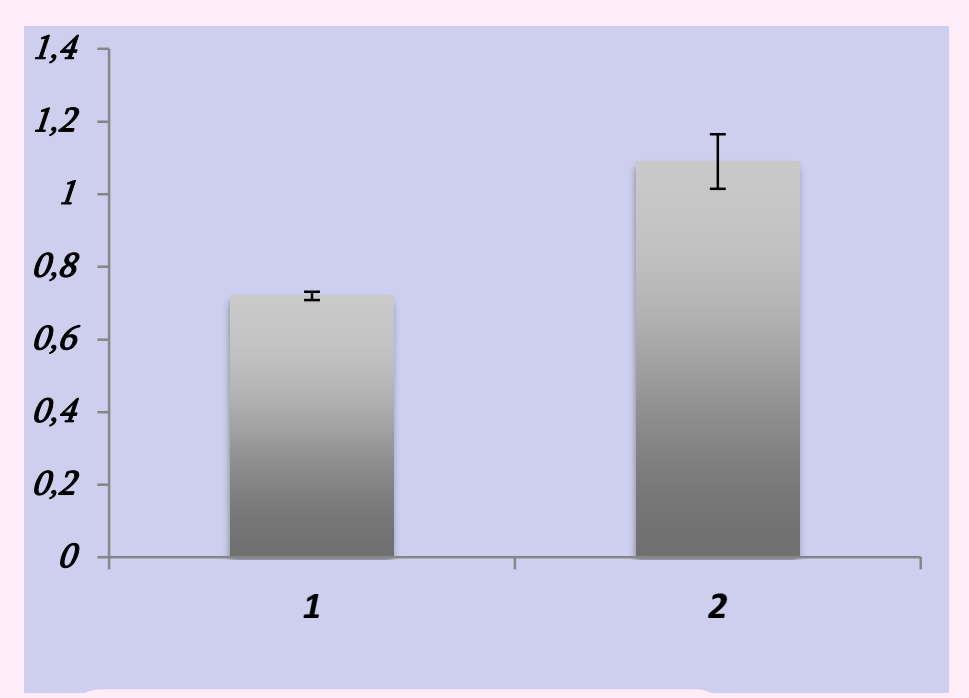

Fig. 2. a. T.

1. Control group

2. Benign Tumo

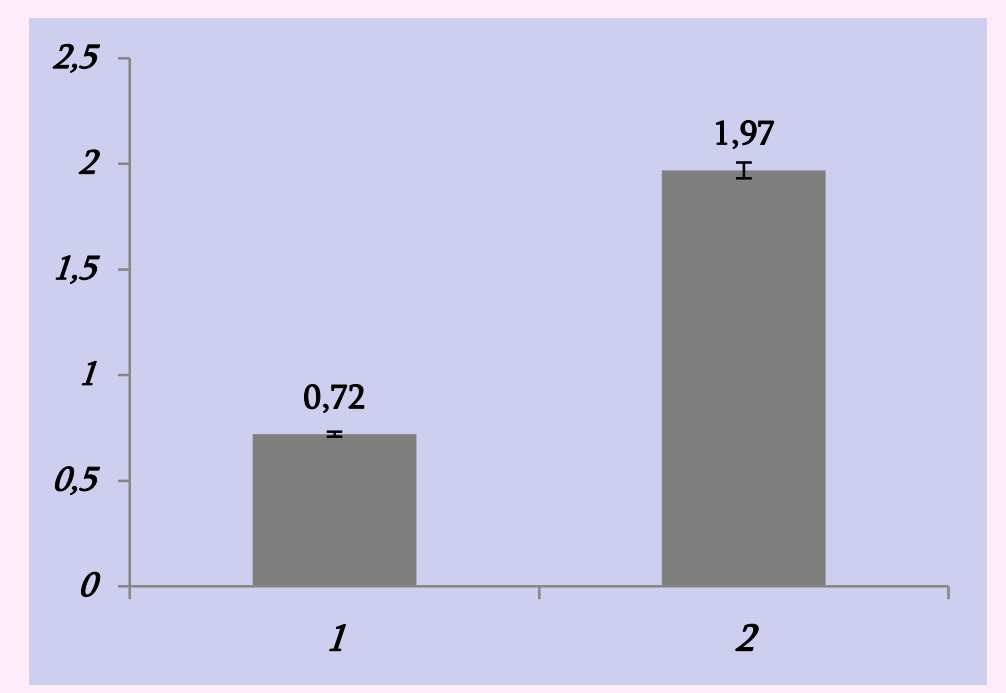

b. T. 1. Control group; 2. Cancer 